\title{
O trabalho de licenciandos em alemão e inglês no PIBID: a construção da prática docente a partir das crenças de alunos do Ensino Médio sobre língua e cultura estrangeira
}

\author{
Cibele Cecilio de Faria Rozenfeld \\ Universidade Estadual Paulista Júlio de Mesquita Filho/Araraquara \\ cibeleroz@gmail.com \\ Ana Cristina Biondo Salomão \\ Universidade Estadual Paulista Júlio de Mesquita Filho/Araraquara \\ ana.salomao@fclar.unesp.br
}

\section{Resumo}

Há algum tempo, pesquisadores na área formação de professores (cf. ZEICHNER; LISTON, 1996; GIMENEZ, 2005) vêm chamando à atenção para a necessidade de inserir licenciandos em contextos de prática que os auxiliem a fazer sentido da formação teórica que recebem no curso de graduação. Neste artigo, discutimos a intersecção entre escola e universidade no trabalho de formação inicial do professor de línguas estrangeiras por meio de atividades desenvolvidas no âmbito do PIBID-Letras de uma universidade estadual, que tiveram como objetivo, de um lado, promover a reflexão sobre o conceito de cultura e o ensino intercultural de línguas durante a formação inicial do professor e, por outro, a desconstrução de estereótipos, de alunos do Ensino Médio, sobre língua e cultura alemã e inglesa. Partindo da análise dos dados sobre crenças de alunos da escola e do suporte teórico de estudos como os de Kramsch (2006, 2009), Bolognini (1993), entre outros, foram elaboradas oficinas voltadas para a ampliação do universo cultural dos alunos do Ensino Médio da escola estadual parceira, do conceito de cultura e para a desconstrução de estereótipos. Verificou-se que a atividade contribuiu para a formação reflexiva dos bolsistas/licenciandos em relação ao tratamento da temática cultura no ensino de línguas.

Palavras-chave: ensino e aprendizagem de línguas, crenças, cultura, formação inicial, PIBID. 


\section{Abstract}

For some time, researchers in teacher education (ZEICHNER; LISTON, 1996; GIMENEZ, 2005) have been drawing attention to the need to place undergraduates in contexts of practice that help them make sense of the theoretical training they receive in the graduation course. In this article, we discuss the intersection between school and university for initial foreign language teacher education through activities carried out under the Brazilian Institutional Program for Initiation to Teaching - Language and Literature of a state university. These activities were aimed, on the one hand, to promote reflection about the concept of culture and intercultural language teaching during initial teacher education and, secondly, to deconstruct stereotypes of high school students about German and English language and culture. Based on the analysis of data on the beliefs of students of the school and the support of theoretical studies such as Kramsch (2006, 2009), Bolognini (1993), among others, workshops were designed to expand the cultural universe of the high school students in the partner state school, the concept of culture and to deconstruct stereotypes. It was found that the activity contributed to the reflective education of the undergraduate students in relation to the treatment of the subject culture in language teaching.

Keywords: foreign language teaching, beliefs, culture, pre-service teacher education, Brazilian Institutional Program for Initiation to Teaching.

\section{Introdução}

Muitas das práticas educacionais referentes ao ensino de cultura na aprendizagem de línguas parecem ainda dominadas por uma visão de culturas nacionais homogêneas, com a prescrição de comportamentos (KRAMSCH, 2009a; SALOMÃO, 2011), tidos como modos de vida "bons" e "apropriados" (KRAMSCH, 2009b), com visões de superioridade e inferioridade de valores que geralmente são impostos pela 'cultura' dominante. Esse tipo de ensino geralmente provoca a proliferação de estereótipos baseados em generalizações e simplificações prejudiciais ao desenvolvimento do pensamento reflexivo, que acabam por gerar caricaturas unidimensionais (KUMARAVADIVELU, 2008; SANTOS; MELLO, 2010).

Acreditamos que mudanças na maneira como apresentamos cultura em sala de aula de língua estrangeira só virão à tona por meio da inserção de tal temática na formação inicial de professores de línguas, tanto do ponto de vista teórico quando por meio de situações que envolvam a prática 
docente e a reflexão sobre ela. Uma das portas encontradas por nós para adentrar tal terreno foi o Programa Institucional Brasileiro de Iniciação à Docência (PIBID), um programa da CAPES que visa incentivar a prática docente na formação inicial.

Neste artigo, discutimos uma experiência realizada no subprojeto PIBID-Letras, que vem sendo desenvolvido desde o primeiro semestre de 2014 por alunos de uma universidade do interior de São Paulo em uma escola estadual na mesma cidade. A experiência consistiu na realização de uma atividade que se iniciou com o levantamento das crenças acerca das línguas alemã e inglesa e das culturas dos países falantes de tais idiomas entre os alunos do Ensino Médio da escola. A partir da análise de tais crenças, foram preparadas e realizadas oficinas pelos bolsistas/licenciandos, as quais serão descritas e analisadas neste artigo.

Para tanto, elaboramos inicialmente o aporte teórico que sustenta a discussão contida no artigo, e posteriormente apresentamos a análise e discussão dos dados coletados no projeto. Por fim, tecemos nossas considerações finais, buscando elucidar de que forma o desenvolvimento do trabalho contribuiu para a reflexão sobre a intersecção entre escola e universidade no trabalho com o conceito de cultura e interculturalidade na formação inicial do professor de línguas estrangeiras.

\section{Reflexões teóricas}

As análises que apresentaremos neste trabalho estarão ancoradas prioritariamente em três eixos teóricos: nas teorias e nos estudos que discorrem sobre as crenças de alunos e/ou professores de línguas estrangeiras (BARCELOS, 2001; 2006; ROZENFELD, 2007; SILVA, 2010), sobre o conceito de cultura na aprendizagem de línguas (MORAN, 2001; KRAMSCH, 2006a,b; RISAGER, 2006; 2007) e a perspectiva intercultural no ensino de línguas estrangeiras (BOLOGNINI, 1993; BYRAM, 2000; ROZENFELD; VIANA, 2011).

Os estudos acerca das crenças em nosso campo de interesse iniciaram-se, de acordo com Barcelos (2004), com Hosenfeld (1978), primeiro pesquisador da área de ensino de LE a pesquisar as crenças de aprendizes, se referindo a elas como "miniteorias de aprendizagem de línguas", e definindo-as como "o conhecimento tácito dos alunos". 
Barcelos (2001) aponta para a existência de diferentes termos para denominar o fenômeno na Linguística Aplicada (LA), como representações dos aprendizes (HOLEC, 1987), filosofia de aprendizes de línguas (ABRAHAM; VANN, 1987), conhecimento metacognitivo (WENDEN, 1986) e cultura de aprender e ensinar línguas (ALMEIDA FILHO, 1993; BARCELOS, 1995). A autora afirma, com base em Freeman (1991), que o pluralismo de rótulos não é necessariamente algo negativo, mas sim o reconhecimento de um fenômeno, o que na concepção de Silva, Rocha e Sandei (2005) demonstra a importância das crenças no âmbito da LA e a necessidade de mais pesquisas nesta área.

Silva (2010) faz um abrangente levantamento das inúmeras pesquisas sobre crenças no ensino e aprendizagem de línguas e conclui que os estudos têm enfocado quatro grandes grupos: crenças de professores (pré-serviço ou em serviço); crenças de alunos; a relação entre crenças de professores e alunos; e crenças de terceiros. A relevância de tais pesquisas se baseia no fato de que é necessário conhecer o universo implícito de professores e alunos, assim como de outros agentes envolvidos, como pais, diretores, coordenadores, pois eles irão de alguma forma, influenciar o processo educativo.

Rozenfeld (2007), com base em Bernat (2005) e Breen (2001), afirma que a identificação de crenças sobre a língua e a cultura alvo e a reflexão acerca do impacto que elas podem ter no processo de aprendizagem e no ensino da língua podem fornecer informações importantes para a elaboração de práticas apropriadas de ensino (ROZENFELD, 2007, p.36). Por essa razão, é de grande importância que o professor reflita sobre as crenças de alunos, sobre suas possíveis origens e seus impactos. Affonso (2003), pesquisadora da área de educação, aponta em seu trabalho para o fato de que a resistência em renunciar a conceitos "antigos" pode muitas vezes dificultar a adoção de novas hipóteses e posturas na aprendizagem. De acordo com a autora, o processo de adoção de novas hipóteses envolve não apenas a construção cognitiva ou racional dos sujeitos, mas inclui ainda aspectos afetivos e socioculturais, referentes aos seus sentimentos, valores e crenças.

Neste trabalho iremos analisar as crenças ${ }^{1}$ dos alunos do Ensino Médio, apoiando-nos na definição e categorização de crenças elaborada por

${ }^{1}$ Utilizamos a noção de crenças no sentido proposto por Barcelos, segundo a qual elas são "uma forma de pensamento, construções da realidade, maneiras de ver e 
Rozenfeld (2007, p. 103-108), segundo a qual as crenças de alunos de línguas estrangeiras sobre a língua e a cultura alvo podem ser classificadas, em três categorias: crenças tipicalizadas, crenças comparativas e crenças relativizadas (op. cit. 2007, p. 103-108) ${ }^{2}$.

As crenças tipicalizadas são definidas como aquelas de configuração mais estereotipada, não apenas no sentido negativo (por exemplo: língua difícil, povo frio), mas também em alguns sentidos considerados de caráter positivo (por exemplo: o povo alemão é organizado, disciplinado, pontual). Elas têm origem na memória coletiva, são marcadas por imagens e mitos e têm como característica a ausência de reflexão do sujeito sobre elas e de embasamento objetivo para sua configuração. Sua origem está em generalizações tecidas socialmente ou em referências etnocêntricas, muitas vezes propagadas pela mídia. De acordo com a autora, as crenças desta categoria geralmente provocam um distanciamento do aluno de LE em relação à língua e/ou à cultura alvo, por um sentimento de não identificação, não pertencimento e não reconhecimento.

As crenças comparativas são marcadas pela comparação explícita da língua e cultura alvo com a materna, ou com outra LE já conhecida e são expressas pelas conjunções comparativas mais...que; ou menos...que, ou ainda comparado $a$. Já as crenças relativizadas são aquelas menos marcadas pelos clichês existentes em uma determinada cultura acerca de uma língua, um povo e uma cultura estrangeira. Geralmente elas se constituem a partir do reconhecimento ou da revisão de estereótipos, marcando maior aproximação da língua e cultura alvo. (ROZENFELD, 2007, p. 103).As crenças relativizadas têm as crenças mistas como subcategoria e são constituídas por crenças tipicalizadas, porém, com elementos modalizadores (por exemplo, língua difícil, mas não impossível). (op.cit., 2007, p. 103).

perceber o mundo e seus fenômenos, co-construídas em nossas experiências resultantes de um processo interativo de interpretação e (re)significação. Como tal, crenças são sociais (mas também individuais), dinâmicas, contextuais e paradoxais" (BARCELOS, 2006, p.18).

${ }^{2}$ No trabalho da autora, a categorização foi estabelecida para as crenças de alunos de alemão como língua estrangeira. Entretanto, tomamos as categorias para analisar crenças sobre alunos também de inglês como LE, pois entendemos que o fenômeno pode ser transposto também para esta situação. 
Para a descrição e discussão das crenças sobre uma língua e uma cultura estrangeira, faz-se necessário tomar também como pressuposto os conceitos de cultura e de interculturalidade na aprendizagem de línguas.

Risager (2007) afirma que a história da pedagogia de ensino de cultura até a década de 1960 foi amplamente baseada no conceito de "realia", descrita como uma tradição puramente informativa de cultura, com 'coisas' ou artefatos da cultura alvo trazidos para o ensino em sala de aula, que poderiam ser textos na língua alvo, livros e objetos de viagem que trouxessem informações práticas sobre o lugar de destino. Segundo a autora, a partir da década de 1970, esforços foram feitos para que o ensino de cultura saísse de uma posição marginal e, coincidindo com a expansão do conceito de texto, foram introduzidos textos que não somente os literários no ensino de línguas, como: vários tipos de ficção, textos de revistas e jornais, menus, placas, entre outros.

Foi ainda nessa década que se convencionou estabelecer a diferença entre Cultura e cultura. A Cultura seriam os grandes feitos de um povo, que se refletem em sua história, instituições sociais, obras de arte, arquitetura, música e literatura, e, por outro lado, a cultura, com c minúsculo, seriam os costumes, tradições e práticas cotidianas das pessoas. Kramsch (1993, 2006a, 2009b) insere estas duas perspectivas de cultura sob a égide do pensamento modernista, segundo o qual o termo 'cultura' está associado ao contexto no qual a língua é vivenciada e falada por seus falantes nativos, vistos como uma comunidade nacional um tanto quanto homogênea com suas instituições, costumes e modo de vida de longa data.

Kramsch (2006a) atribui a visão de Cultura a uma tradição humanista que conceitua cultura como um produto de conhecimento literário e artístico canônico da 'cultivada' classe-média, que foi instrumental na construção e promoção do Estado-nação no século XIX. A autora explica que, com o advento do ensino comunicativo de línguas, na década de 1980, o conceito humanista de cultura deu lugar a um conceito mais pragmático de cultura como modo de vida, a partir de estudos da sociolinguística e da pragmática sobre uso apropriado da linguagem em contextos culturais autênticos. Entretanto, para a autora não houve avanço em termos de ensino crítico de cultura, uma vez que professores passaram a ensinar regras de uso sociolinguístico do mesmo modo como ensinavam regras de uso gramatical.

Segundo Risager (2007), na década de 1980, o conceito antropológico de cultura se torna referência comum, trazendo também a 
ideia do ensino de línguas como uma tarefa intercultural, uma vez que a pedagogia de ensino de cultura passou a se interessar no conhecimento trazido pelos alunos sobre seus próprios países, suas percepções de si mesmos e de sua identidade nacional. Do encontro entre culturas distintas nasce então a noção de interculturalidade, comunicação intercultural, ensino intercultural e competência intercultural. Segundo Kumaravadivelu (2008), tais noções estão intimamente atreladas ao conceito de hibridismo cultural, que ganhou espaço na educação de línguas durante os anos 90, como por exemplo nas propostas de Kramsch $(1993,1998)$ e de Lo Bianco, Liddicoat e Crozet (1999), apontando para a interação intercultural como uma busca por um lugar intermediário, que não mantém a estrutura cultural do aprendiz nem busca assimilar a do outro, mas faz do participante um experienciador (experiencer) da diferença (e não observador).

A partir de tais estudos origina-se a visão, hoje amplamente difundida, de que alunos de LE não necessitam apenas do conhecimento e de habilidades para o manejo da gramática da língua-alvo, mas também da habilidade de usar a língua de forma social e culturalmente adequada. (cf. KRAMSCH, 1993; GUERREIRO, 2005; ROZENFELD; VIANA, 2011; dentre outros). Guerreiro (2005) postula que o professor deve usar estratégias para que o aluno desenvolva consciência crítica sobre aspectos culturais da LE ancorados na própria cultura e difíceis de serem compreendidos.

Tomamos neste artigo a noção de interculturalidade reformulada por Kramsch (2006b, 2009a), que busca transpor seu caráter estático e limitado a uma cultura nacional, entendendo-a como um processo contínuo, que faz parte da subjetividade dos aprendizes, os quais não são apenas comunicadores e solucionadores de problemas, mas pessoas inteiras com corações, corpos e mentes, com memórias, fantasias, lealdades, identidades.

Ainda, concordamos com Busnardo (2010, p. 130) que, na perspectiva da pós-modernidade, existem múltiplas culturas em cada país, e cada uma está em fluxo. O estático é substituído pelo dinâmico; a "camisa de força" pelo "verbo". São colocadas em questão, sobretudo, noções de "cultura nacional" e o "essencialismo cultural" 3 , passando-se a pensar em identidades múltiplas - de etnia, gênero, religião, grupo profissional, etc.

${ }^{3}$ Segundo Risager (2006), um entendimento essencialista de cultura é a concepção de cultura como algo que tem uma essência específica, ou seja, formada por características que podem ser precisamente definidas ou descritas, 
Assim, cultura é um processo constitutivo, construída na interação, o que gera para o ensino de línguas a importância de não se associar uma língua a uma cultura e vice-versa, mas abranger questões que levam em conta a subjetividade do aprendiz e o caráter híbrido e dinâmico que a noção de cultura tem na contemporaneidade.

Tomando como base a fundamentação teórica apresentada, discutiremos, a seguir, as crenças de estudantes do Ensino Médio sobre a língua e alemã e inglesa e seus falantes, assim como apresentaremos os procedimentos adotados com vistas à desconstrução de crenças e ensino de cultura pelos bolsistas/licenciandos.

\section{O subprojeto PIBID Letras, os dados e a proposta de intervenção na escola}

O PIBID tem como objetivo:

(...) inserir os licenciandos no cotidiano de escolas da rede pública de educação, proporcionando-lhes oportunidades de criação e participação em experiências metodológicas, tecnológicas e práticas docentes de caráter inovador $e$ interdisciplinar que busquem a superação de problemas identificados no processo de ensino e aprendizagem (BRASIL, $2013, s / p)^{4}$

O subprojeto PIBID-Letras vem sendo desenvolvido desde o início do ano de 2014 em uma escola estadual em parceria com uma universidade pública, ambas no interior de São Paulo, e constitui-se de 30 bolsistas das áreas de alemão, inglês, italiano, espanhol e francês. Cada área conta com 6 bolsistas, que são divididos em três grupos. Cada grupo (A, B e C) é composto por 10 alunos (2 de cada área) e é responsável pelo desenvolvimento de atividades específicas.

Neste trabalho, analisaremos uma das atividades realizadas pelos bolsistas/licenciandos dos subprojetos de alemão e inglês do Grupo B,

independentemente de contexto, e que pode ser usado como fator explicativo em relação às ações e atitudes das pessoas de determinada cultura.

4 Maiores informações podem ser obtidas pelo link: http://www.capes.gov.br/educacao-basica/capespibid 
responsável pela organização de eventos culturais, visando à reflexão e discussão sobre aspectos relacionados às culturas das diferentes línguas estrangeiras. Tal atividade foi a primeira realizada por eles no âmbito dos subprojetos e consistiu na realização de entrevistas com alunos de uma escola estadual, com objetivo de fazer um inventário das imagens que eles possuem sobre o alemão e o inglês, os povos e as culturas-alvo. A partir das respostas encontradas, os bolsistas/licenciandos planejaram oficinas, buscando desconstruir estereótipos identificados e discutir aspectos relacionados às culturas dos países e povos mencionados.

\section{Crenças sobre língua e cultura alemã e inglesa}

Analisando as crenças sobre a língua alemã, conforme esperado, foi grande a incidência de crenças do tipo tipicalizadas (língua rude, difícil de falar, de pronúncia forte, com muitas consoantes $)^{5}$. Um dos alunos entrevistados mencionou até mesmo a imagem de que a língua dá a impressão de que "as pessoas estão prontas para declarar guerra", que está em conformidade com as crenças tipicalizadas relacionadas à língua alemã (ROZENFELD, 2007).

Todavia, os bolsistas/licenciandos se surpreenderam com um aluno que expressou ter interesse em aprender a língua "desde a infância", por considerar uma língua interessante, diferente, apesar de esta lhe parecer de pronúncia difícil. Tal fato aponta para uma especificidade das crenças que as diferem de características do construto "atitude". Tal característica é mencionada por Rozenfeld (2007, p. 32), segundo a qual o conceito "atitude" envolve uma predisposição para ação coerente, enquanto as crenças podem gerar ação paradoxal a elas. Neste sentido, a crença de língua de fonética difícil não impediu que este aluno desenvolvesse interesse em aprender o alemão.

Os alunos entrevistados demonstraram estar imbuídos de crenças tipicalizadas também no que se refere à aparência do povo alemão: todos mencionaram que os alemães são "branquinhos, altos, loiros, de olhos

${ }^{5}$ O programa PIBID-Letras oferece nesta escola também oficinas de língua alemã e alguns alunos que foram entrevistados e frequentavam tais aulas expressaram crenças relativizadas sobre a língua: de gramática difícil no início, mas de fácil leitura. 
azuis", apesar de haver grande número de alemães morenos. As crenças se caracterizam ainda como tipicalizadas no que se refere ao perfil dos alemães, na medida em que grande parte dos alunos os avalia como inteligentes, sérios. Notamos, porém, a presença de algumas crenças relativizadas, tendo em vista que alguns não os percebem como pessoas frias, mas como "normais" ou ainda "não necessariamente frias ou sérias".

Os bolsistas/licenciandos perceberam a partir da entrevista que o conhecimento sobre personagens e objetos da cultura alemã era bastante restrito ao senso comum, ou seja, a jogadores de futebol, carros, cerveja, guerra (Hitler). Quando perguntados sobre os países nos quais o alemão é a língua oficial, a maioria mencionou Alemanha e Áustria e alguns mencionaram ainda a Suíça. Tal fato diferencia os resultados geralmente apresentados no senso comum, na medida em que comumente o alemão é tido como língua oficial apenas da Alemanha.

Em relação à língua inglesa, crenças tipicalizadas foram percebidas no que tange à associação de tal língua aos Estados Unidos e à Inglaterra. Os bolsistas/licenciandos comentaram que os alunos entrevistados muitas vezes confundiram países com cidades, e que as mais citadas foram: Las Vegas, Los Angeles, Nova York e Londres. A maioria dos entrevistados afirmou que gostaria de aprender a língua inglesa para poder visitar uma dessas cidades ou também a Disney World. Em relação aos elementos associados por eles a tal língua, destacaram-se "aspectos da indústria midiática estadunidense, como o cinema hollywoodiano, a música pop/rock; a culinária típica, como hot dog, hambúrgueres e geleia de amendoim; e também, pontos turísticos, como a Estátua da liberdade, o Central Park, a Casa Branca e o Big Ben."6

Notamos que, de modo geral, as crenças são muito mais voltadas a elementos advindos dos EUA, como o cinema, a música, a comida e os monumentos, sendo somente dois elementos associados à Inglaterra: a cidade de Londres e o monumento Big Ben. Isso foi percebido pelos bolsistas/licenciandos e usado para construir o seu trabalho nas oficinas, como podemos ver em seus relatos:

Os alunos possuem um conceito ao mesmo tempo coerente com os reais aspectos da cultura inglesa, mas também um pouco

${ }^{6}$ Excerto obtido em relatório de bolsista sobre a entrevista com alunos do EM, publicado na plataforma moodle. 
distorcidos. Esperamos com o trabalho em cultura desmistificar algumas noções que eles têm dos Estados Unidos, da Inglaterra, do Canadá e da Irlanda e trabalhar com outros países também falantes de língua inglesa que nem os próprios alunos tinham ciência, como é o caso da África do Sul, da Índia, da Nova Zelândia e da Austrália (Bolsista/licenciando de inglês 1, relato no moodle).

A ida a escola realmente nos ajudou a perceber a necessidade e o conhecimento prévio dos alunos e como devemos abordar os temas. Conversamos com o máximo de alunos que conseguimos e convidamos todos a participar do workshop, inclusive das outras línguas. Eles se mostraram entusiasmados. (Bolsista/licenciando de inglês 2, relato no moodle).

Vemos aqui a importância de inserir o professor em formação inicial no contexto em que atuará para que, por meio do contato com alunos e a realidade escolar, possa compreender as bases que deverão direcionar sua prática pedagógica, como a análise de necessidades e do conhecimento prévio e interesses dos alunos. Se queremos formar professores reflexivos, que sejam capazes de identificar dificuldades relacionados a sua prática educacional e de buscar caminhos para lidar com elas (ZEICHNER; LISTON, 1996), é importante que tenham experiências como essas já na formação inicial, na qual eles mesmos buscarão examinar, entender e lidar com problemas de sua prática de sala de aula. No caso do PIBID, essa experiência é feita em colaboração com os outros bolsistas/licenciandos, com o supervisor, que é um professor da escola, na qual os bolsistas estão atuando, e com o coordenador, que é o professor universitário responsável pelo projeto. Essa rede formada pela parceria de duas instituições distintas, professores formadores em cada uma delas e um grupo de estudantes em formação em relação de discussão e troca constante de experiências vai ao encontro de propostas de ação na formação de professores contemporâneas como Dutra e Mello (2004), Vieira-Abrahão (2004) e Gimenez (2004, 2005). De acordo com as autoras, é necessário propiciar aos licenciandos em Letras um contexto de prática com suporte de profissionais experientes, assim como a oportunidade de vivenciar nele experiências colaborativas, que os auxiliará a identificar e desenvolver estratégias para lidar com a realidade que encontrarão em sua prática docente. 
Tomando como base os dados das entrevistas, os bolsistas/licenciandos PIBID da área de alemão e inglês, sob orientação das docentes coordenadoras de tais atividades, elaboraram oficinas ${ }^{7}$ (uma de alemão e uma de inglês, respectivamente), que focalizaram os elementos que descreveremos a seguir. Tais oficinas buscaram realizar um trabalho que se baseou na noção de cultura como construção dinâmica entre as pessoas (MORAN, 2001), consistindo em valores, significados e crenças que as pessoas criam em suas circunstâncias sociais, que são únicas. Deste modo, cultura não é algo estático, um corpo fixo de conhecimento, mas algo em constante evolução, sendo construído através das relações interpessoais, sempre no processo do vir a ser.

\section{As intervenções pedagógicas dos alunos por meio das oficinas}

Descreveremos e discutiremos as ações nas oficinas dos bolsistas/licenciandos de alemão e inglês na escola por meio de tópicos que condensam os aspectos que nos pareceram mais salientes na análise dos dados coletados no ambiente Moodle, no qual os bolsistas/licenciandos postavam seus planejamentos das oficinas e diários reflexivos, mostrando de que modo o trabalho foi construído ao longo do semestre, com o auxílio de reuniões para debates e apoio teórico.

\subsection{Abrangência da língua alemã e da língua inglesa}

Em relação à língua alemã, ainda que os alunos entrevistados tivessem mencionado a Áustria e a Alemanha como países que a têm como língua oficial, considerou-se relevante abordar o fato de que o alemão é uma língua falada por 180 milhões de pessoas, sendo 100 milhões delas como língua materna, colocando-a como a segunda língua nativa mais falada na Europa ${ }^{8}$. Apontaram que ela é a língua oficial não apenas da Alemanha, mas da Suíça, Áustria, parte da Itália e Lichtenstein.

${ }^{7}$ As oficinas focalizaram os temas a partir da utilização de diferentes materiais e mídias: apresentação PREZI, fotos, músicas e trechos de filmes.

${ }^{8}$ Os números foram obtidos em diferentes sites disponíveis na rede, dentre eles a wikipedia 
Além disso, os estudantes enfatizaram ainda a importância do alemão no Brasil, uma vez que isso não havia sido mencionado por nenhum aluno entrevistado: o alemão é falado por aproximadamente 1 milhão de imigrantes no Brasil, sendo a maioria residente na região sul ${ }^{9}$.

No que tange à língua inglesa, os bolsistas/licenciandos discutiram a questão do inglês como língua franca, abordando primeiramente a formação histórica da língua e seu desenvolvimento como língua de comunicação mundial, buscando ir além da visão de que essa língua 'pertence' aos ingleses, norte-americanos e canadenses.

Além disso, trabalharam com a apresentação de canções regionais de alguns países, nos quais se fala a língua inglesa como língua oficial, que não haviam sido citados na entrevistas com os alunos do Ensino Médio, como a Nova Zelândia, a Guiana Inglesa (ou Guiana Britânica) e a África do Sul.

\subsection{Conceito de cultura, a noção de próprio e de "outro"}

$\mathrm{Na}$ oficina dos bolsistas/licenciandos de alemão, ${ }^{10}$ a partir da percepção de que a noção de cultura dos alunos estava muito atrelada à Cultura (MORAN, 2001; KRAMSCH, 2006a), na medida em que caracterizam como importantes marcas a civilização e seus grandes feitos (carro-BMW, salsicha, cerveja, etc), foram apresentados outros elementos que fazem parte do cotidiano e da vida alemã contemporânea, como o muro de Berlim, seus grafites, caricaturas de personagens da política (como da primeira ministra), concertos de música contemporânea em bares de cidades, comidas que têm origem em outras culturas e que já foram incorporadas às práticas alimentares do povo alemão (Fondue: Suíça, Döner Kebab: Turquia) e um evento de banda inglesa que marcou profundamente a cultura alemã: o show dos Beatles em Hamburgo (com a música "Sie liebt dich", cantada, tocada e gravada pelos Beatles em alemão).

9 Nesse contexto os bolsistas discutiram algumas das informações contidas no endereço: http://brasilalemanha.com.br/novo_site/

${ }^{10} \mathrm{Na}$ oficina optou-se por abordar prioritariamente aspectos relacionados à Alemanha, e não aos outros países que têm o alemão como idioma oficial. Tal fato foi explicitado aos alunos das oficinas, após serem indicados os demais países. 
Para dar o enfoque da temática, os bolsistas/licenciandos partiram de figuras selecionadas previamente por eles que ilustravam alguns hábitos e elementos tidos como característicos ou não da cultura alemã e os utilizaram para desencadear toda a discussão sobre o conceito de cultura e de estereótipos. Partindo de frases apresentadas como "os italianos são caóticos", "espanhóis são arrogantes" e outras, e ainda de um filme disponibilizado no YouTube (Meet the germans ${ }^{11}$ ), os bolsistas provocaram debates sobre estereótipos, a noção de "outro", sobre clichês acerca dos alemães e a importância de refletirmos sobre tais julgamentos. Essa discussão foi finalizada com a discussão do texto "Das bunte Deutschland" (A Alemanha colorida) ${ }^{12}$, que discorre sobre a diversidade de nacionalidades que reside hoje na sociedade alemã, composta por imigrantes de países como Turquia, Grécia, Portugal, Espanha, e outros, e sobre personalidades da mídia alemã que têm raízes em outros países como uma apresentadora de noticiário (Linda Zervakis: originalmente da Grécia), um humorista famoso (Bülent Ceylan: filho de pai turco) e o apresentador Tarek Youzbachi (de antepassados sírios).

O trabalho prático dos bolsistas nas oficinas foi conduzido a partir de reuniões semanais, na quais se discutia a temática e o planejamento das ações. Além disso, foram sugeridos textos para leitura que pudessem nortear os trabalhos, estabelecendo uma teorização sobre os conceitos de língua e cultura. Pudemos notar o reflexo da interação entre teoria e prática nos relatos dos alunos em seus relatórios parciais, nos quais eles conjugam a dimensão cultural a questões de ordem política e social:

As diferenças culturais são de importância política por se tratarem de conflitos de poder e controle (Bolsista/licenciando de inglês 2, relatório parcial).

Durante a leitura do texto "Semiótica social e estereótipos: uma análise na comunicação intercultural" da autora Polianne Merie Espindola foi possível depreender que atualmente o contato com culturas diversas serviu como disseminação de um conceito de culturalidade voltado para o conhecimento do outro ao invés do

${ }^{11}$ Disponível em https://www.youtube.com/watch?v=9x5Apqzo6aI. Acesso em 03 de julho de 2014.

12 Disponível em http://goethezentrumbrasilia.blogspot.com.br/2013/10/typischdeutsch-das-bunte-deutschland.html. Acesso em 03 de julho de 2014. 
estranhamento. (...) A política etnocêntrica é por várias vezes aplicada na formação de conhecimento de uma cultura alheia. (Bolsista/licenciando de inglês 1, relatório parcial).

Tais reflexões serviram de base para o planejamento de ações nas quais se buscou descontruir o estranhamento da cultura do outro, as quais discutiremos a seguir.

\subsection{O "outro" está em mim}

O trabalho de 'desestranhamento' da cultura do outro nas oficinas dos bolsistas/licenciandos de inglês foi feito por meio da discussão sobre estrangeirismos na língua portuguesa, principalmente advindos da língua inglesa, com a utilização de histórias em quadrinho e tirinhas cômicas. Houve também uma oficina preparada a partir do filme "A sociedade dos poetas mortos", na qual os alunos trouxeram um trecho de tal filme e realizaram atividades para gerar "a reflexão dos alunos acerca de pontos significativos do sistema educacional, da passagem pelo ensino médio, os anseios para o futuro e sobre o modo de olhar para a vida" (Bolsista/licenciando de inglês 1 , relato no moodle). Tal trabalho buscou mostrar que algumas questões, como as citadas no excerto do relato do bolsista, são universais e fazem parte da natureza humana, estando muitas vezes atreladas também a questões de organização social.

Os bolsistas/licenciandos do alemão abordaram grandes invenções de alemães que marcaram nossa sociedade contemporânea, mas que pareceram ser desconhecidas dos alunos como: a imprensa de Gutenberg (1440), a cerveja (1516), a homeopatia (1797), a gaita (1821), o jeans (1873), a bacteriologia (1876), a motocicleta (1885), o carro (1886), o raio X (1895), a aspirina (1879), a garrafa térmica (1903), a pasta de dente (1903), o filtro de café (1908), o sachê de chá (1929), o scanner (1951), a pílula anticoncepcional (1961), o chip (1969), o airbag (1971), etc. ${ }^{13}$.

Ainda que tais informações relacionem-se mais diretamente à cultura nacional, ou seja, aos objetos produzidos na civilização alemã, optou-se por levá-las aos alunos para buscar despertar neles a percepção de

${ }^{13}$ Informações disponíveis em http://www.welt.de/wirtschaft/karriere/leadership/article12202607/50-

Erfindungen-die-die-Welt-veraenderten.html. Acsso em 03 de julho de 2014. 
que nossa Cultura também é marcada e configurada a partir da Cultura do outro, uma vez que encontramos todos estes objetos profundamente inseridos e já "invisíveis" 14 em nosso cotidiano.

Foram também abordados alguns conflitos que podem surgir entre pessoas de nacionalidades distintas, em decorrência da incompreensão do comportamento do "outro" como diferente, mas de sua interpretação como estranho. A discussão foi baseada em situações concretas, como por exemplo, que alemães podem ser tomados por frios apenas pelo fato de se cumprimentarem com um aperto de mão e não com um beijo na face. Nesse sentido, buscou-se mostrar também que diferenças e problemas apontados na interação intercultural poderiam ser interpretados de modo diferente na comunicação entre pessoas que têm a mesma língua e cultura nacionais, mas que geralmente atribui-se a diferença entre comportamentos a distintas visões de mundo de pessoas que pertencem a diferentes culturas, enfocando somente a dimensão da coletividade e esquecendo-se que o indivíduo faz escolhas e é produtor e produtor de cultura.

\subsection{Considerações Finais}

A área de formação de professores de línguas busca hoje caminhos para realizar a construção de uma identidade profissional do professor de línguas voltada para questões contemporâneas sobre língua, sociedade e cultura, na qual se articulem a reflexões teórico-críticas com os domínios da prática. Acreditamos que um dos caminhos para que se consiga trabalhar com estereótipos e visões essencialistas de cultura, as quais desprezam a complexidade do ser humano, têm necessariamente de perpassar a formação inicial do professor.

Neste trabalho, buscamos tecer reflexões sobre uma experiência realizada por parte do grupo da equipe do Programa Institucional Brasileiro de Iniciação Docente (PIBID), do subprojeto Letras de uma universidade do interior paulista, nos trabalhos desenvolvidos com alunos do Ensino

${ }^{14}$ De acordo com Bax (2006 ) uma nova tecnologia geralmente causa, após seu surgimento, uma primeira reação de rejeição. $O$ autor propõe então fases de normalização da tecnologia: da rejeição até que ela se torne "invisível”, ou seja, até que ela se integre completamente na vida das pessoas e seu uso se torne-se naturalizado no cotidiano 
Médio de uma escola estadual. As atividades descritas tiveram como objetivo, de um lado, levar os licenciandos/bolsistas das áreas de inglês e alemão a pensarem na prática de ensino de línguas estrangeiras como processo que envolve muito mais que o ensino de estruturas linguísticas ou de dados geográficos sobre as culturas-alvos: envolve também a percepção do conceito de cultura em um sentido mais amplo e de ensino de cultura articulado com o 'desestranhamento' do outro em relação ao próprio e do próprio como constituído pelo “outro". Para tanto, apoiamo-nos em estudos teóricos como os de Moran (2001), Kramsch (cf.1993, 2006, 2009), Kumaravadivelu (2008), Salomão (2011), entre outros. Por outro lado, buscou-se promover entre alunos do Ensino Médio a reflexão sobre estereótipos acerca da língua e cultura alvo, a partir de um levantamento de suas crenças (Rozenfeld, 2007; Rozenfeld; VIANA, 2011) e da discussão sobre aspectos culturais que envolvem as línguas estrangeiras inglês e alemão.

A proposta demonstrou se adequar à visão contemporânea de formação inicial de professores de línguas estrangeiras pautada na articulação teoria e prática, no paradigma reflexivo de formação de professores (VIEIRA-ABRAHÃO, 2004; ZEICHNER, LISTON, 1996) e de ensino de ensino intercultural de ensino de línguas (BOLOGNINI, 1998; BYRAM, 2000; ROZENFELD, 2007; ROZENFELD; VIANA, 2011). A partir do trabalho desenvolvido foi possível levar os bolsistas/licenciandos a refletirem sobre a importância de se analisar as necessidades, interesses e conhecimento prévio dos alunos ao planejar as aulas, assim como pensar sobre o papel do componente cultural no ensino de LE, por meio da inserção de tal temática na formação inicial dos professores de línguas, tanto com base em estudos teóricos quanto em articulação com a prática docente.

\section{Referências}

AFFONSO, Suselei A.B. O papel das crenças e dos valores na construção de novos conhecimentos: um estudo na perspectiva dos modelos organizadores do pensamento. 2003. Dissertação (Mestrado em Educação) - Faculdade de Educação, Universidade Estadual de Campinas, Campinas, 2003. 
BARCELOS, Ana Maria F. Metodologia de pesquisa das crenças sobre aprendizagem de línguas: estado da arte. Revista Brasileira de Linguística Aplicada, v. 1, n. 1, p. 71-92, 2001.

. Cognição de professores e alunos: tendências recentes na pesquisa de crenças sobre ensino e aprendizagem de línguas. In: BARCELOS, A. M. F.; VIEIRA-ABRAHÃO, M. H. (Orgs.). Crenças e Ensino de Línguas: Foco no professor, no aluno e na formação de professores. Campinas, SP: Pontes Editores, 2006. p. 15-42.

BOLOGNINI, Carmen Zink. Estereótipos e ensino intercultural. Projekt, n. 10, p. 21-25, 1993.

BYRAM, MiCHAEL. Assessing intercultural competence in language teaching. Sprogforum, Kobenhavn, v. 6, n. 18, p. 8 - 13, 2000.

BRASIL, Coordenação de Aperfeiçoamento de Pessoal de Nível Superior. Portaria $n^{\circ} 96$ de 18 de julho de 2013: Novo regulamento do Programa Institucional de Bolsa de Iniciação à Docência - PIBID. Disponível em http://www.capes.gov.br/images/stories/download/legislacao/Portaria 096 18 jul13 AprovaRegulamentoPIBID.pdf. Acesso em: 18/07/2014.

BUSNARDO, Joanne. Contextos pedagógicos e conceitos de cultura no ensino de línguas estrangeiras. In: SANTOS, Percilia; ALVAREZ, Maria Luiza Ortiz (Orgs.). Língua e cultura no contexto de português língua estrangeira. Campinas: Pontes, 2010. p. 123-139.

DUTRA, Deise Prina; MELLO, Heliana. A prática reflexiva da formação inicial e continuada de professores de língua inglesa. In: VIEIRA ABRAHÃO, Maria Helena (Org.). Prática de Ensino de Língua Estrangeira: experiências e reflexões. Campinas: Pontes, 2004. p.31-43.

GIMENEZ, Telma. Tornando-se professores de inglês: experiências de formação inicial em um curso de Letras. In: VIEIRA ABRAHÃO, Maria Helena (Org.). Prática de Ensino de Língua Estrangeira: experiências e reflexões. Campinas: Pontes, 2004. p.171-187. 
. Desafios contemporâneos na formação de professores de línguas: contribuições da linguística aplicada. In: FREIRE, Maximina M.; VIEIRAABRAHÃ̃O, M.H.; BARCELOS, Ana Maria Ferreira (Orgs.). Linguística Aplicada e contemporaneidade. Campinas: ALAB/Pontes, 2005. p.183201.

GUERREIRO, G. M. S. Cultura, linguagem e ensino de língua estrangeira: um estudo acerca desta inter-relação. 2005. 123f. Dissertação (Mestrado em Linguística Aplicada) - Instituto de Letras, Uiversidade Estadual de São Paulo, São José do Rio Preto, 2005.

KRAMSCH, Claire. Context and Culture in Language Teaching. Oxford: Oxford University Press, 1993.

. Language and culture. Oxford: Oxford University Press, 1998.

. Culture in language teaching. In: BROWN, K. (Ed.). Encyclopedia of Language and Linguistics. Vol. 3. 2nd edition. Oxford: Elsevier Science, 2006a. p. 322-329.

. From communicative competence to symbolic competence. The Modern Language Journal, v. 90, n. 2, p. 249-252, 2006 b.

. The multilingual subject. What language learners say about their experience and why it matters. Oxford: Oxford University Press, 2009a.

. Cultural perspectives on language learning and teaching. In: KNAPP, Karlfried; SEIDLHOFER, Barbara (Eds.). Handbook of foreign language communication and learning. Berlin: Mouton de Gruyter, 2009b. p. 219-245.

KUMARAVADIVELU, B. Cultural Globalization and Language Education. USA: Yale University Press, 2008.

LO BIANCO, Joseph; LIDDICOAT, Anthony J.; CROZET, Chantal. Intercultural competence: From language policy to language education. In: J. Lo Bianco; A. Liddicoat; C. Crozet (Eds.). Striving for the third place: 
O trabalho de licenciandos em alemão e inglês no PIBID...

Intercultural competence through language education. Melbourne: Language Australia, 1999. p. 113-125.

MORAN, Patrick R. Teaching culture: perspectives in practice. Canada: Heinle \& Heinle, 2001.

RISAGER, Karen. Language and Culture: global Flows and Local Complexity. Clevedon: Multilingual Matters, 2006.

- Language and Culture Pedagogy: from a national to a transnational paradigm. Clevedon: Multilingual Matters, 2007.

ROZENFELD, Cibele C.F.. Crenças sobre uma língua e cultura-alvo (alemã) em dimensão intercultural de ensino de língua estrangeira. 2007. 197f. Dissertação (Mestrado em Linguística). UFSCar, São Carlos, SP. :

ROZENFELD, C.C.F; VIANA, N.. O desestranhamento em relação ao alemão na aprendizagem do idioma: um processo de aproximação ao "outro" sob a perspectiva da competência intercultural. Pandaemonium ger. (Online) [online]. 2011, n.17, pp. 259-288. ISSN 1982-8837. <http://dx.doi.org/10.1590/S1982-88372011000100014>.

SALOMÃO, Ana Cristina B. A cultura e o ensino de língua estrangeira: perspectivas

para a formação continuada no projeto teletandem Brasil. 2011. 268p. Tese (Doutorado em Estudos Linguísticos). Unesp, São José do Rio Preto, SP.

SANTOS, Danúsia Torres; MELLO, Ana Catarina Moraes Ramos Nobre. Entre a praia e a nau: reflexões em torno dos conceitos de identidade e competência intercultural em contexto de ensino de PLE. In: SANTOS, Percilia; ALVAREZ, Maria Luiza O. (Orgs.). Língua e cultura no contexto de português língua estrangeira. Campinas: Pontes, 2010. p. 181-190.

SILVA, Kleber A. Crenças no ensino-aprendizagem e na formação de professores de línguas: delimitando e atravessando fronteiras na linguística aplicada brasileira. In: SILVA, K.A. (Org.). Crenças, discursos \& Linguagem. Vol I. Campinas: Pontes, 2010. p. 21-101. 

; ROCHA, Claudia Hilsdorf; SANDEI, Maria de Lurdes R. A importância do estudo das crenças na formação de professores de línguas. Contexturas: Ensino Crítico de Inglês, APLIESP, v. 8, p. 19-40, 2005.

VIEIRA-ABRAHÃO, Maria Helena. Crenças, pressupostos e conhecimentos de alunos-professores de língua estrangeira e sua formação inicial. In: . (Org.). Prática de Ensino de Língua Estrangeira: experiências e reflexões. Campinas: Pontes, 2004. p. 131-152.

ZEICHNER, Kenneth M.; LISTON, Daniel P. Reflective Teaching: an introduction. New Jersey: Lawrence Erbaum Associates Publishers, 1996.

Submetido em: 19/10/2014 Aceito em: 03/02/2015

Title: The work of undergraduate students of German and English on the Brazilian Institutional Program for Initiation to Teaching: constructing pedagogical practice from high school students' beliefs about foreign language and culture 